\title{
Accurate measurement of pitch-based carbon fiber electrical resistivity
}

\author{
Caroline Jovine Bouças Guimarães ${ }^{1 *}$ (D), Alcino Palermo de Aguiar ${ }^{1}$ (D) and Alexandre Taschetto de Castro \\ 'Departamento de Química, Instituto Militar de Engenharia - IME, Rio de Janeiro, RJ, Brasil \\ Seção de Tecnologia de Materiais de Carbono - STMC, Centro Tecnológico do Exército - CTEx, \\ Rio de Janeiro, RJ, Brasil \\ *caroljovine@gmail.com
}

\begin{abstract}
This study investigated the appropriate methodology required to measure single carbon fibers electrical resistivity. Twoand four-probe methods were evaluated for this measurement. Comparing results for single filaments of pitch-based and PAN-based fibers shows that the two-probe method gives acceptable results for PAN-based fibers, but much higher deviations from adjusted resistivity for pitch-based fibers $(>15 \%)$. The four-probe method shows small deviations $(<1 \%)$ for both precursors and is the most suitable for measurements of pitch-based carbon fibers. The four-probe method gives higher accuracy than the two-probe for all samples tested.
\end{abstract}

Keywords: carbon fiber, four-probe method, mesophase-pitch, electrical resistivity.

How to cite: Guimarães, C. J. B., Aguiar, A. P., \& Castro, A. T. (2021). Accurate measurement of pitch-based carbon fiber electrical resistivity. Polímeros: Ciência e Tecnologia, 31(1), e2021011. https://doi.org/10.1590/0104-1428.08720

\section{Introduction}

Mesophase pitch-based carbon fibers have higher transport properties than most polymers, because of the mesophase pitch's ability to form highly ordered graphite domains ${ }^{[1-7]}$. Therefore, they are used as thermal and electrical management materials in applications such as high thermal conductivity radiators ${ }^{[8,9]}$, electronic packaging ${ }^{[10]}$, electromagnetic interference shielding ${ }^{[11]}$, heat storage ${ }^{[9]}$, and radar absorption ${ }^{[12]}$.

Volume resistivity is an important performance indicator for carbon fibers, applied to the evaluation of process parameters along its production steps: spinning ${ }^{[13-15]}$, stabilization ${ }^{[16,17]}$, carbonization $^{[18,19]}$, and graphitization ${ }^{[19-22]}$. It can also be applied in the evaluation of pre and post-processing steps such as intercalation ${ }^{[23,24]}$, annealing ${ }^{[25]}$, and coating ${ }^{[26-29]}$. Hence, many researchers use single fiber methods to find the correlation between electrical resistivity and other physical properties ${ }^{[30-32]}$.

First proposed by Wenner ${ }^{[33]}$ in 1915 , and adjusted for small, fragile compounds by Coleman ${ }^{[34]}$ in 1975 , the four-probe method is commonly used by carbon fiber researchers ${ }^{[14-20,23-28]}$. However, the carbon fiber resistivity international standard method, ISO 13913, specifies a twoprobe measurement ${ }^{[35]}$, and many authors use which ${ }^{[36-42]}$.

Despite being a simple alternative ${ }^{[43]}$, the two-probe method may be sensitive to contact and lead resistances ${ }^{[44]}$ (Figure 1). Some authors recommend this method only when resistance values are high ${ }^{[45]}$ or when accuracy is not required, as it has a known systematic bias $(20-800 \Omega)^{[38-41]}$. Thus, this information suggests the reference standard single carbon-fiber resistivity test method has some limitations, and it could be inadequate for carbon fibers' electrical resistivity measurements with highly ordered graphite domains such as mesophase pitch-based carbon fibers.

To investigate whether the two methods used in literature are suitable, applied the two- and four-probe to measuring PAN- and pitch-based carbon fibers' electrical resistivity and testing the effect of contact resistance through the linear fitting sample resistances for different gauge lengths. The results were compared with the datasheet values and literature reports.

\section{Materials and Methods}

Standard and high-modulus grades of PAN- and pitchbased carbon fibers were selected (Table 1). For each sample, electrical resistivity measurements for ten single filaments, obtained at room temperature by the two- and four-point methods, were averaged and compared to the manufacturer datasheet values.

Individual filaments were straightened and glued to the specific mounting tab of each method. The two-probe mounting template is a $0.3 \mathrm{~mm}$ thickness cardboard, with a $25 \mathrm{~mm}$ hole cut out. The four-probe arrangement is a printed circuit board with four parallel copper conduction paths, with the two inner trails separated by $25 \mathrm{~mm}$ and the two outer trails by $35 \mathrm{~mm}$. Each carbon monofilament lay on the standard support following a centerline of the mounting template, fixed with a conductive adhesive (Figure 2). 
Table 1. Electrical resistivity $\left(\rho_{0}\right)$, Young Modulus (E), and diameter (D) of commercial fibers specification ${ }^{[46-49]}$.

\begin{tabular}{cccccc}
\hline Manufacturer & Name & $\mathbf{\rho}_{\mathbf{0}}(\boldsymbol{\mu} \boldsymbol{\Omega} . \mathbf{m})$ & $\mathbf{E}(\mathbf{G P a})$ & $\mathbf{D}(\boldsymbol{\mu m})$ & Precursor \\
\hline Cytec & $\mathrm{K}-1100$ & 1.2 & 965 & 10.0 & Pitch \\
Cytec & $\mathrm{P}-25$ & 13 & 159 & 11.0 & Pitch \\
Torayca & M46J & 9 & 436 & 5.0 & PAN \\
Torayca & T300 & 17 & 230 & 7.0 & PAN \\
\hline
\end{tabular}

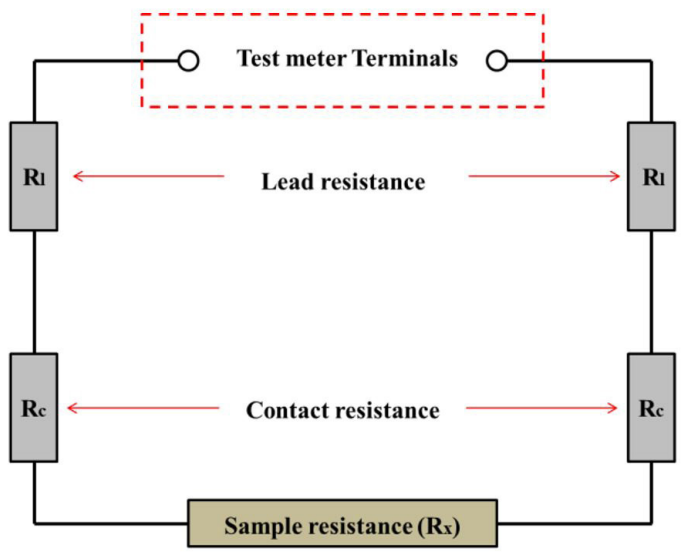

Digital multimeter measurement $=\mathbf{R x}+\mathbf{2} \cdot \mathbf{R} \mathbf{I}+\mathbf{2} \cdot \mathbf{R} \mathbf{c}$

Figure 1. Two-probe method equivalent circuit representation.

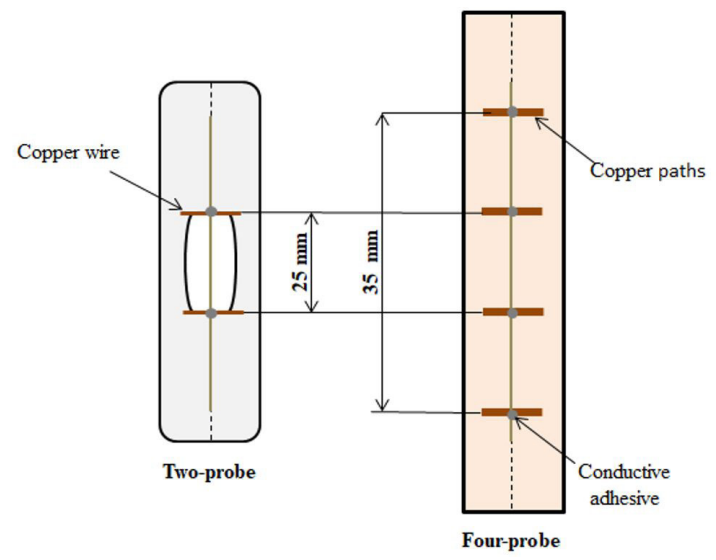

Figure 2. Two and four-probe mounting tab for single filament.

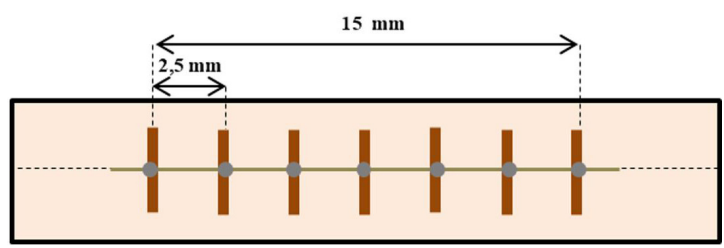

Figure 3. Mounting tab with different gauge length sample for two and four-probe method.

A Mitutoyo CD-6" AX-B digital caliper was used to measure the distances between the two inner points (L) at which the fiber no longer touches the conductive adhesive. An Olympus BX41 confocal microscope was used to measure the diameter (D) at three distinct points along the filament length at 1000x magnification. In the two-probe method, a Fluke $87 \mathrm{~V}$ digital multimeter the electrical resistance (R) of individual filaments. Meanwhile, in the four-probe method, the external contacts were connected through a Keithley's 6221 DC source, and the internal contacts connected through a Keithley's 2182A high impedance nano voltmeter connected the others. Thermal voltage's effects were eliminated by reversing the polarity and averaging the two values ${ }^{[50]}$. Electrical resistance was obtained according to Equation 1.

$$
\rho=\frac{\pi D^{2}}{4 L} \cdot R
$$

The resistance of each sample was also measured by both methods, at different lengths in the $2-15 \mathrm{~mm}$ range (Figure 3 ) to estimate the contact resistance $\left(\mathrm{R}_{c}\right)$ and the adjusted resistivity value $\left(\rho_{\mathrm{a}}\right)$. These parameters can be obtained by linearly fitting the resistance $\left(\mathrm{R}^{*}\right)$ of different gauge lengths $\left(\mathrm{L}^{*}\right)$, according to Equation 2, assuming that the cross-sectional carbon fiber area (A) and the contact resistance are constant. The adjusted electrical resistivity values were compared to the averages electrical resistivity at the fixed $25 \mathrm{~mm}$ distance.

$$
R^{*}=\rho_{a} \cdot \frac{L^{*}}{A}+R_{c}
$$

\section{Results and Discussions}

Table 2 shows the average electrical resistivity $\left(\bar{\rho}_{\mathrm{i}}\right)$ and relative deviation $\left(D_{i}\right)$ from the manufacturers' values $\left(\rho_{0}\right)$ of each carbon fiber for both tested methods. For the two-probe method, the electrical resistivity relative deviations of the PAN-based fibers are less than $4 \%$, while the pitch-based deviations exceed $10 \%$. In contrast, all relative deviations for the four-probe method are less than $2 \%$. Besides that, at $95 \%$ confidence interval Student's t-test ${ }^{[51]}$ results in no statistically significant difference between the manufacturers' values $\left(\rho_{0}\right)$ and the four-probe method electrical resistivity $\left(\bar{\rho}_{I V}\right)$ (Table 2$)$, since $\mathrm{t}$-values $\left(\mathrm{t}_{\mathrm{IV}}\right)$ modulus are less than the critical t-value $\left(\mathrm{t}_{\text {crit }}=2.26^{[51]}\right)$. On the other hand, the two-probe showed a significant difference between these values for K-1100 and P-25 fiber since the t-values modulus is higher than the t-critical. These results suggest that pitchbased carbon fiber manufacturers do not follow the single filament method proposed by ISO 13913 international standards.

The four-probe standard deviations are smaller than the two-probe for all samples (Table 2). Besides, the former, by statistical F-test ${ }^{[51]}$, provide better precision at 95\% confidence level, since all samples F-value (Table 2) are superior to the critical $\mathrm{F}$-value $\left(\mathrm{F}_{\text {crit }}=3.31^{[51]}\right)$. These 
Table 2. Average electrical resistivity $\left(\bar{\rho}_{\mathrm{i}}\right)$, manufacturers declared value $\left(\rho_{0}\right)$, standard deviation $\left(\sigma_{\mathrm{i}}\right)$, relative deviation $(\mathrm{RD})$ from manufacturers provided value, $\mathrm{t}$ and $\mathrm{F}$ values.

\begin{tabular}{|c|c|c|c|c|c|c|c|c|c|}
\hline \multirow{2}{*}{ Name } & \multicolumn{4}{|c|}{ Two-probes method } & \multicolumn{4}{|c|}{ Four-probes method } & \multirow{2}{*}{$\mathbf{F}$} \\
\hline & $\bar{\rho}_{\mathrm{II}}(\mu \Omega . \mathrm{m})$ & $\sigma_{\mathrm{II}}(\mu \Omega . \mathrm{m})$ & $\mathrm{RD}_{\mathrm{II}}(\%)$ & $t_{I I}$ & $\bar{\rho}_{\mathrm{IV}}(\mu \Omega . \mathrm{m})$ & $\sigma_{\mathrm{IV}}(\mu \Omega . \mathrm{m})$ & $\mathrm{RD}_{\mathrm{IV}}(\%)$ & $t_{\text {IV }}$ & \\
\hline $\mathrm{K}-1100$ & 1.4 & 0.3 & 16.7 & 2.30 & 1.2 & 0.2 & 0.0 & 0.00 & 3.36 \\
\hline P-25 & 11.7 & 1.2 & 10.1 & -3.43 & 12.8 & 0.6 & 1.9 & -1.05 & 4.00 \\
\hline M46J & 8.9 & 0.6 & 1.1 & -0.53 & 8.9 & 0.3 & 1.1 & -1.05 & 4.00 \\
\hline T300 & 16.4 & 1.7 & 3.5 & -1.12 & 16.8 & 0.8 & 1.2 & -0.79 & 4.52 \\
\hline
\end{tabular}

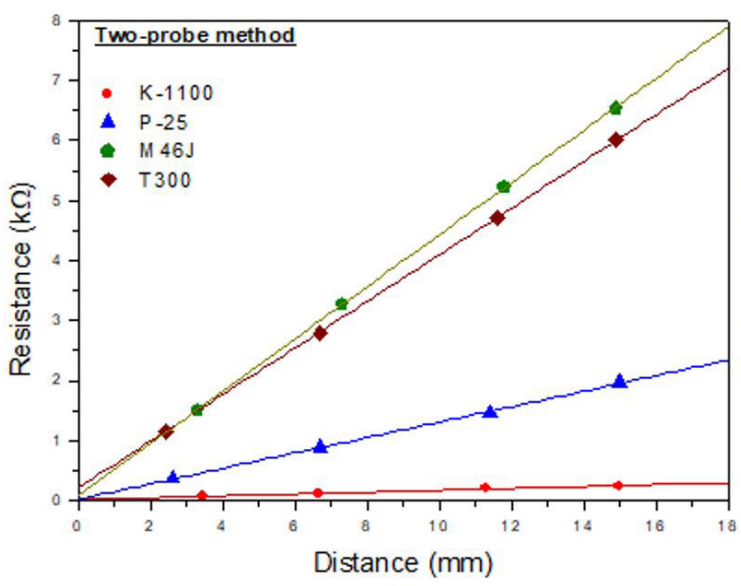

(a)

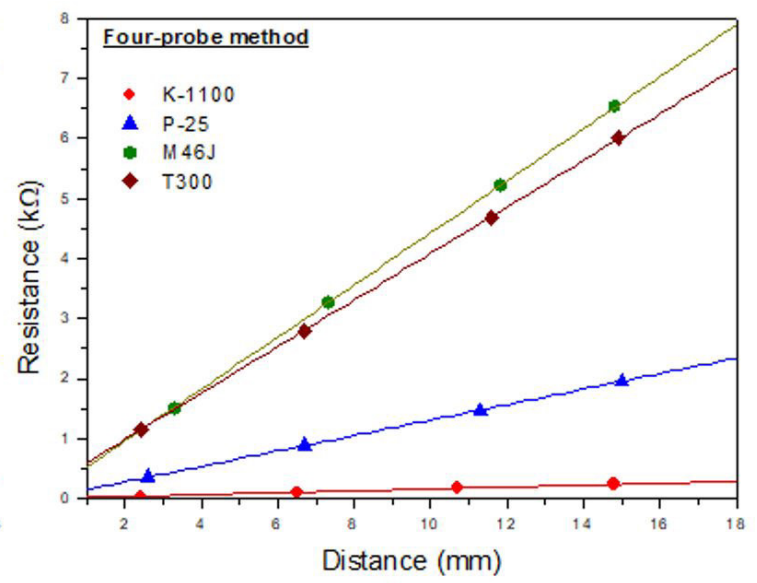

(b)

Figure 4. Commercial carbon fibers fit of (a) two-probe and (b) four-probe methods.

results suggest that the four-probe is more accurate than the two-probe method.

Table 3 shows each carbon fiber's literature data electrical resistivity $\left(\rho_{L}\right)$. Comparing these to two- and four-probe the electrical resistivity $\left(\rho_{I I}\right.$ and $\rho_{I V}$ ) by Student's t-test concludes that is no statistically significant difference in a 95\% confidence interval (Table 3 ) since the $t$-values ( $t_{\text {IV }}$ ) modulus are less than the critical t-value for all sample. On the other hand, there is a significant difference between literature data and two-probe electrical resistivity values for K-1100 fiber since t-values modulus is higher than the t-critical. This result indicates that the two-probe may not be a suitable method to estimate the pitch-based carbon fibers' electrical properties.

Figure 4 shows the correlations between measured electrical resistance and gauge length, fitted by a straight line, for both methods. Contact resistance is given by the vertical axis intercept, and electrical resistivity by the line slope (Table 4). All correlation coefficients $\left(\mathrm{R}^{2}\right)$ were higher than 0.999 , representing a good fit.

Contact resistances varied from about $20-220 \Omega$, with the highest values from PAN-based carbon fibers. For these fibers, there was no significant difference between two and four probes contact resistance. However, for pitch-based carbon fibers, the contact resistance obtained by the twoprobe method is significantly higher than by the four-probe method. These results confirm the higher accuracy of the four-probe method ${ }^{[44]}$.

For all samples, the adjusted electrical resistivity obtained by the two and four-probe methods were identical.
Table 3. Literature data $\left(\rho_{\mathrm{L}}\right)$, standard deviation $\left(\sigma_{\mathrm{i}}\right)$, and $\mathrm{t}$ values for two- and four- probe results.

\begin{tabular}{lccc}
\hline \multicolumn{1}{c}{ Name } & $\boldsymbol{\rho}_{\mathbf{L}}(\boldsymbol{\mu} \boldsymbol{\Omega} \cdot \mathbf{m})$ & $\mathbf{t}_{\mathrm{II}}$-value & $\mathbf{t}_{\mathrm{IV}}$-value \\
\hline K-1100 & $1.17^{[52]}$ & 2.65 & 0.47 \\
$\mathbf{P - 2 5}$ & $13.7^{[53]}$ & -1.84 & 2.11 \\
M46J & $9.3^{[54]}$ & -1.84 & -1.95 \\
T300 & $16.8^{[55]}$ & -0.74 & 0.00 \\
\hline
\end{tabular}

Comparison of average values for the adjusted electrical resistivity $\left(\rho_{\mathrm{a}}\right)$ and the electrical resistivity $\left(\bar{\rho}_{i}\right)$ obtained by the four-probe method, by Student's t-test ${ }^{[51]}$ show no statistically significant difference in a $95 \%$ confidence interval. For the two-probe method, on the other hand, there is a significant difference between these values for K-1100 and P-25 fibers, which are both pitch-based.

Besides having low resistivity, the P-25 and K-1100 fibers' electrical resistances are the lowest because they have the largest diameter (Table 1), so its values are more affected by contact resistance (Table 5). The lowest electrical resistance fiber, K-1100, presented the highest relative deviation from adjusted resistivity, while the highest electrical resistance fiber, M46J, presented the smallest difference. This effect is more prominent in two-probe measurements, which is the method that has higher contact resistances.

The coefficient of variation (Table 5), variability estimator, from pitch-based carbon fibers is higher than PAN-based; this occurs because pitch-based fibers tend to be more heterogeneous than PAN-based ${ }^{[56]}$, which intensifies measurement noise. 
Table 4. Contact resistance $\left(\mathrm{R}_{\mathrm{c}}\right)$, adjusted electrical resistivity $\left(\rho_{\mathrm{a}}\right)$, and coefficient of determination $\left(\mathrm{R}^{2}\right)$

\begin{tabular}{|c|c|c|c|c|c|c|}
\hline \multirow{2}{*}{ Name } & \multicolumn{3}{|c|}{ Two-probe method } & \multicolumn{3}{|c|}{ Four-probe method } \\
\hline & $\mathbf{R}_{\mathrm{c}}^{\mathrm{II}}(\mathbf{\Omega})$ & $\rho_{\mathrm{a}}^{\mathrm{II}}(\mu \Omega \cdot \mathrm{m})$ & $\mathbf{R}^{2}$ & $R^{I V}(\Omega)$ & $\rho^{I V}(\mu \Omega \cdot m)$ & $\mathbf{R}^{2}$ \\
\hline $\mathrm{K}-1100$ & 17 & 1.2 & 0.99936 & 5 & 1.2 & 0.99999 \\
\hline $\mathrm{P}-25$ & 25 & 12.9 & 0.99979 & 8 & 13.0 & 0.99966 \\
\hline M46J & 90 & 8.9 & 0.99992 & 92 & 8.9 & 0.99973 \\
\hline $\mathrm{T} 300$ & 215 & 16.7 & 0.99993 & 211 & 16.7 & 0.99998 \\
\hline
\end{tabular}

Table 5. Average electrical resistance $(\overline{\boldsymbol{R}})$, relatives deviation (RD) from adjusted resistivity, and relative standard deviation (RSD).

\begin{tabular}{cccccc}
\hline Name & $\overline{\boldsymbol{R}}(\mathbf{k} \boldsymbol{\Omega})$ & $\mathbf{R D}_{\mathrm{II}} \mathbf{( \% )}$ & $\mathbf{R D}_{\mathrm{IV}} \mathbf{( \% )}$ & $\mathbf{R S D}_{\mathbf{I I}} \mathbf{( \% )}$ & $\mathbf{R S D}_{\mathbf{I V}} \mathbf{( \% )}$ \\
\hline $\mathrm{K}-1100$ & 0.5 & 16.7 & 0.8 & 23 & 15 \\
P-25 & 2.8 & 9.3 & 0.5 & 10 & 5 \\
T300 & 10.0 & 2.0 & 0.4 & 7 & 3 \\
M46J & 11.4 & 0.3 & 0.3 & 10 & 5 \\
\hline
\end{tabular}

\section{Conclusions}

The two-probe method specified by ISO resulted in up to $2 \%$ relative deviation from adjusted resistivity for PAN-based fibers and over $15 \%$ deviation for pitch-based fibers. On the other hand, the four-probe method achieved less than $1 \%$ relative deviation from adjusted resistivity for all tested fibers, producing accurate and consistent results, even when measuring low resistances.

We conclude that the two-probe method is particularly inadequate for determining pitch-based carbon fiber's electrical resistivity due to its inability to measure low electrical resistances accurately. For PAN-based fibers, the two-probe method gives acceptable results, but with lower accuracy than the four-probe method unless its values are corrected by linear fitting of the resistance of different gauge lengths.

\section{Acknowledgements}

We thank the Brazilian Army Technological Center (Centro Tecnológico do Exército - CTEx) for supporting this work.

\section{References}

1. Singer, L. S. (1977). US Patent 4,005,183. United States. from https://patents.google.com/patent/ US4005183A/en

2. Otani, S., Watanabe, S., \& Araki, T. (1977). US Patent 4,016,247. United States. from https://patents.google.com/ patent/US4016247A/en

3. Singer, L. S. (1978). The mesophase and high modulus carbon fibers from pitch. Carbon, 16(6), 409-415. http://dx.doi. org/10.1016/0008-6223(78)90085-4.

4. Bright, A. A., \& Singer, L. S. (1979). The electronic and structural characteristics of carbon fibers from mesophase pitch. Carbon, 17(1), 59-69. http://dx.doi.org/10.1016/00086223(79)90071-X.

5. Singer, L. S. (1981). Carbon fibres from mesophase pitch. Fuel, 60(9), 839-847. http://dx.doi.org/10.1016/0016-2361(81)901472.

6. Matsumoto, T. (1985). Mesophase pitch and its carbon fibers. Pure and Applied Chemistry, 57(11), 1553-1562. http://dx.doi. org/10.1351/pac198557111553.

7. Rogers, D. K., Jones, S. P., Fain, C. C., \& Edie, D. D. (1993). Graphitization of a high-sulfur mesophase pitch-based fiber.
Carbon, 31(2), 303-313. http://dx.doi.org/10.1016/00086223(93)90035-9.

8. Goncharov, K., Panin, Y., Balykin, M., \& Khmelnitsky, A. (2016). High thermal conductive carbon fiber radiators with controlled loop heat pipes. In 46th International Conference on Environmental Systems (pp. 10-14). Vienna, Austria: ICES Steering Committee, American Institute of Chemical Engineers - AIChE, American Society of Mechanical Engineers - ASME, ICES International Committee - INT. Retrieved in 2020, September 29, from http://hdl.handle.net/2346/67639

9. Yamada, K., Nagano, H., Kobayashi, Y., \& Totani, T. (2014). Heat Storage Panel Using a Phase-change Material Encapsulated in a High-thermal conductivity CFRP for Micro Satellites. In 44th International Conference on Environmental Systems (pp. 13-17). Tucson, Arizona: ICES Steering Committee, ICES International Committee - INT. Retrieved in 2020, September 29, from http://hdl.handle.net/2346/59577

10. Zweben, C. (1998). Advances in composite materials for thermal management in electronic packaging. Journal of the Minerals, 50(6), 47-51. http://dx.doi.org/10.1007/s11837-998- 0128-6.

11. Lee, J., Liu, Y., Liu, Y., Park, S. J., Park, M., \& Kim, H. Y. (2017). Ultrahigh electromagnetic interference shielding performance of lightweight, flexible, and highly conductive copper-clad carbon fiber nonwoven fabrics. Journal of Materials Chemistry. C, Materials for Optical and Electronic Devices, 5(31), 7853-7861. http://dx.doi.org/10.1039/C7TC02074K.

12. Neo, C. P., \& Varadan, V. K. (2004). Optimization of carbon fiber composite for microwave absorber. IEEE Transactions on Electromagnetic Compatibility, 46(1), 102-106. http://dx.doi. org/10.1109/TEMC.2004.823618.

13. Hamada, T., Nishida, T., Sajiki, Y., Matsumoto, M., \& Endo, M. (1987). Structures and physical properties of carbon fibers from coal tar mesophase pitch. Journal of Materials Research, 2(6), 850-857. http://dx.doi.org/10.1557/JMR.1987.0850.

14. Barnes, A. B., Dauché, F. M., Gallego, N. C., Fain, C. C., \& Thies, M. C. (1998). As- spun orientation as an indication of graphitized properties of mesophase-based carbon fiber. Carbon, 36(7-8), 855-860. http://dx.doi.org/10.1016/S00086223(97)00166-8.

15. Gallego, N. C., \& Edie, D. D. (2001). Structure property relationships for high thermal conductivity carbon fibers. Composites. Part A, Applied Science and Manufacturing, 32(8), 1031-1038. http://dx.doi.org/10.1016/S1359-835X(00)00175-5.

16. Beauharnois, M. E., Edie, D. D., \& Thies, M. C. (2001). Carbon fibers from mixtures of AR and supercritically extracted mesophases. Carbon, 39(14), 2101-2111. http:// dx.doi.org/10.1016/S0008-6223(01)00045-8. 
17. Yuan, G., Li, X., Xiong, X., Dong, Z., Westwood, A., Li, B., Ye, C., Ma, G., Cui, Z., Cong, Y., Zhang, J., \& Li, Y. (2017). A comprehensive study on the oxidative stabilization of mesophase pitch-based tape-shaped thick fibers with oxygen. Carbon, 115, 59-76. http://dx.doi.org/10.1016/j.carbon.2016.12.040.

18. Karacan, I., \& Meşeli, H. (2018). Characterization of amorphous carbon fibers produced from thermally stabilized polyamide fibers. Journal of Industrial Textiles, 47(6), 1185-1211. http:// dx.doi.org/10.1177/1528083716682922.

19. Shi, K., Yang, J., Li, J., Zhang, X., Wu, W., Liu, H., Yoon, S. H., \& Li, X. (2020). Effect of oxygen-introduced pitch precursor on the properties and structure evolution of isotropic pitch-based fibers during carbonization and graphitization. Fuel Processing Technology, 199, 106291. http://dx.doi. org/10.1016/j.fuproc.2019.106291.

20. Jones, S. P., Fain, C. C., \& Edie, D. D. (1997). Structural development in mesophase pitch-based carbon fibers produced from naphthalene. Carbon, 35(10-11), 1533-1543. http://dx.doi. org/10.1016/S0008-6223(97)00106-1.

21. Wu, G.-P., Li, D.-H., Yang, Y., Lu, C.-X., Zhang, S.-C., Li, X.-T., Feng, Z.-H., \& Li, Z. H. (2012). Carbon layer structures and thermal conductivity of graphitized carbon fibers. Journal of Materials Science, 47(6), 2882-2890. http://dx.doi.org/10.1007/ s10853-011- 6118-z. PMid:25170190.

22. Qian, X., Zhi, J., Chen, L., Zhong, J., Wang, X., Zhang, Y., \& Song, S. (2018). Evolution of microstructure and electrical property in the conversion of high strength carbon fiber to high modulus and ultrahigh modulus carbon fiber. Composites Part A: Applied Science and Manufacturing, 112, 111-118. http:// dx.doi.org/10.1016/j.compositesa.2018.05.030.

23. Gaier, J. R. (1984). Stability of bromine intercalated graphite fibers. Boston: American Physical Society - APS.

24. Lee, W. D., Davis, G. P., \& Vogel, F. L. (1985). Electrical resistivity and magneto resistance of carbon/graphite fibers intercalated with nitric acid and arsenic pentafluoride. Carbon, 23(6), 731-737. http://dx.doi.org/10.1016/0008-6223(85)902350.

25. Yang, H., Yoon, S. H., Korai, Y., Mochida, I., \& Katou, O. (2003). Improving graphitization degree of mesophase pitchderived carbon fiber by solid-phase annealing of spun fiber. Carbon, 41(3), 397-403. http://dx.doi.org/10.1016/S00086223(02)00320- 2.

26. Ryu, S. K., Kim, S. Y., Gallego, N., \& Edie, D. D. (1999). Physical properties of silver-containing pitch-based activated carbon fibers. Carbon, 37(10), 1619-1625. http://dx.doi. org/10.1016/S0008-6223(99)00086-X.

27. Tzeng, S. S., \& Chang, F. Y. (2001). Electrical resistivity of electroless nickel coated carbon fibers. Thin Solid Films, 388(12), 143-149. http://dx.doi.org/10.1016/S0040-6090(01)00809-4.

28. Tzeng, S. S., \& Chang, F. Y. (2001). EMI shielding effectiveness of metal-coated carbon fiber-reinforced ABS composites. Materials Science and Engineering A, 302(2), 258-267. http:// dx.doi.org/10.1016/S0921-5093(00)01824-4.

29. Xing-Wen, J., Xin, Z., Jun-Meng, L., \& Ping, W. (2018). Conductivity and conducting stability of copper-coated carbonfiber-reinforced cement-based composite. Materials Research Express, 5(9), 095705. http://dx.doi.org/10.1088/2053-1591/ aad 98 b.

30. Lavin, J. G., Boyington, D. R., \& Lahijani, J. (1993). The correlation of thermal conductivity with electrical resistivity in mesophase pitch-based carbon fiber. Carbon, 31(6), 10011002. http://dx.doi.org/10.1016/0008-6223(93)90207-Q.

31. Zhang, X., Fujiwara, S., \& Fujii, M. (2000). Measurements of thermal conductivity and electrical conductivity of a single carbon fiber. International Journal of Thermophysics, 21(4), 965-980. http://dx.doi.org/10.1023/A:1006674510648.
32. Ouyang, Q., Liu, D., Jiang, X., Ma, H., Chen, Y., \& He, L. (2018). Quantitative structure-property relationships of polyacrylonitrile-based graphite fibers revealed by laser confocal Raman spectroscopy. Spectroscopy Letters, 51(2), 89-95. http://dx.doi.org/10.1080/00387010.2018.1425304.

33. Wenner, F. (1915). A method of measuring earth resistivity. National Bureau of Standards, US Government Printing Office. 12, 478-496.

34. Coleman, L. B. (1975). Technique for conductivity measurements on single crystals of organic materials. The Review of Scientific Instruments, 46(8), 1125-1126. http://dx.doi.org/10.1063/ 1.1134370 .

35. International Organization for Standardization - ISO. Carbon fibre - Determination of volume resistivity ISO 13931. (2013). Switzerland: ISO.

36. Owston, C. N. (1970). Electrical properties of single carbon fibres. Journal of Physics. D, Applied Physics, 3(11), 16151626. http://dx.doi.org/10.1088/0022-3727/3/11/309.

37. Sundaray, B., Subramanian, V., \& Natarajan, T. S. (2005). Electrical Properties of Electrospun Poly(Ethylene Oxide) Polypyrrole Composite Fibers. MRS Online Proceedings Library, 889, 308. http://dx.doi.org/10.1557/PROC-0889-W03-08.

38. Castellanos-Gomez, A. (2013). A simple method to characterize the electrical and mechanical properties of micro-fibers. European Journal of Physics, 34(6), 1547-1554. http://dx.doi. org/10.1088/0143-0807/34/6/1547.

39. Gant, P., Niu, Y., Svatek, S. A., Agraït, N., Munuera, C., GarcíaHernández, M., Frisenda, R., de Lara, D. P., \& Castellanos-Gomez, A. (2017). Lithography-free electrical transport measurements on 2D materials by direct microprobing. Journal of Materials Chemistry. C, Materials for Optical and Electronic Devices, 5(43), 11252-11258. http://dx.doi.org/10.1039/C7TC01203A.

40. Niu, Y., Frisenda, R., Svatek, S. A., Orfila, G., Gallego, F., Gant, P., Agraït, N., Leon, C., Rivera-Calzada, A., De Lara, D. P., Santamaria, J., \& Castellanos-Gomez, A. (2017). Photodiodes based in $\mathrm{La}_{0.7} \mathrm{Sr}_{0.3} \mathrm{MnO}_{3}$ /single layer $\mathrm{MoS}_{2}$ hybrid vertical heterostructures. $2 D$ Materials, 4(3), 034002. http://dx.doi. org/10.1088/2053-1583/aa797b

41. Yanhong, T., Weizhe, H., \& Xuejun, Z. (2017). Comparison of methods for the measurement of the resitivity of carbon fibers. Journal of Beijing University of Chemical Technology, 44, 34-37.

42. Mizuno, Y., Shindo, Y., Kawakita, K., Kusashi, Y., Ohsawa, Y., Satou, H., Akama, H., \& Horie, H. (2018). US Patent 2018/0,090,762. United States. from https://patents. justia. com/patent $/ 20180090762$

43. Rebouillat, S., \& Lyons, M. E. G. (2011). Measuring the electrical conductivity of single fibres. International Journal of Electrochemical Science, 6(11), 5731-5740.

44. Miccoli, I., Edler, F., Pfnür, H., \& Tegenkamp, C. (2015). The 100th anniversary of the four-point probe technique: the role of probe geometries in isotropic and anisotropic systems. Journal of Physics Condensed Matter, 27(22), 223201. http://dx.doi. org/10.1088/0953-8984/27/22/223201. PMid:25985184.

45. Yanhong, T., Weizhe, H., \& Xuejun, Z. (2017). Research on measuring method of volume resistivity of carbon fiber bundle. Journal of Beijing University of Chemical Technology, 44(1), 34-37. http://dx.doi.org/10.1016/j.compositesa.2014.10.015.

46. SOLVAY. P-25 Technical Data Sheet. (2020). Retrieved in 2020, September 29, from www.cytec.com

47. TORAY. T300 Technical Data Sheet Rev 6: Updated April 13, 2018. Retrieved in 2020, September 29, from www.toraycma.com

48. TORAY. M46J Technical Data Sheet Rev. 1: Updated April 13, 2018. Retrieved in 2020, September 29, from www.toraycma.com

49. SOLVAY. K1100 Technical Data Sheet. Retrieved in 2020, September 29, from www.cytec.com 
50. Cigoy, D. (2010). Accurate low-resistance measurements start with identifying sources of error. Cleveland, Ohio: Keithley Instruments, Inc. Retrieved in 2020, September 29, from https:// download.tek.com/document/LLResistWhitePaper.pdf

51. Montgomery, D. (2019). Introduction to Statistical Quality Control. Arizona, USA: John Wiley \& Sons.

52. Yuan, G., Xuanke, L., Westwood, A., Dong, Z., Rand, B., Cui, Z., Cong, Y., Zhang, J., Li, Y., Zhang, Z., \& Wang, J. (2014). The structure and properties of ribbon-shaped carbon fibers with high orientation. Carbon, 68, 426-439. http://dx.doi. org/10.1016/j.carbon.2013.11.019.

53. Xiang, X., \& Chung, D. D. L. (2019). Colossal electric permittivity discovered in polyacrylonitrile (PAN) based carbon fiber, with comparison of PAN-based and pitch-based carbon fibers. Carbon, 145, 734-739. http://dx.doi.org/10.1016/j. carbon.2019.01.069.
54. Yamane, T., Katayama, S., Todoki, M., \& Hatta, I. (1996). Thermal diffusivity measurement of single fibers by an ac calorimetric method. Journal of Applied Physics, 80, 43584365. http://dx.doi.org/10.1063/1.363394.

55. Fengmei, H., Jianping, L., Conghui, C., Zhenglong, Z., \& Yinjie, S. (2010). Evaluation and characterization on electric resistivity of carbon fiber. Aerospace Materials \& Technology, 40(2), 109-111.

56. Huson, M. G., Church, J. S., Kafi, A. A., Woodhead, A. L., Khoo, J., Kiran, M. S. R. N., Bradby, J. E., \& Fox, B. L. (2014). Heterogeneity of carbon fibre. Carbon, 68, 240-249. http:// dx.doi.org/10.1016/j.carbon.2013.10.084.

Received: Sept. 29, 2020

Revised: Feb. 26, 2021

Accepted: Mar. 21, 2021 